\title{
PEMBERIAN AIR REBUSAN DAUN SALAM (Syzygium polyanthum) TERHADAP PENURUNAN KADAR ASAM URAT PADA PENDERITA ASAM URAT DI DUSUN KADISORO DESA GILANGHARJO KECAMATAN PANDAK KABUPATEN BANTUL DIY TAHUN 2017
}

\author{
Pramukti Dian Setianingrum $^{1^{*}}$, Istika Dwi Kusumaningrum ${ }^{2}$, Dwi Kurnia Rini ${ }^{3}$ \\ 1,2,3 STIKES Surya Global Yogyakarta. \\ Email: ${ }^{1}$ Pramukti.skm@gmail.com, ${ }^{2}$ dwikurniarini@gmail.com, ${ }^{3}$ istikadk@gmail.com
}

\begin{abstract}
Abstrak
Asam urat adalah senyawa dalam air yang merupakan hasil akhir metabolism purin. Tanda dan gejalanya yaitu peradangan pada sendi yang tertekan, terasa nyeri, dan kemerahan pada daerah yang telah terjadi asam urat, kekakuan serta pembengkakan pada sendi yang tertekan. Data posyandu lansia di dusun kadisoro terdapat 64 lansia menyatakan mempunyai keluhan asam urat. Daun salam di Dusun Kadisoro belum dimanfaarkan sebagai obat herbal karena tidak mengetahui fungsi dan manfaat dari daun salam tersebut. Tujuan dari penelitian ini adalah untuk mengetahui pengaruh pemberian air rebusan daun salam (Syzygium polyanthum) terhadap penurunan kadar asam urat pada penderita asam urat di Dusun Kadisoro Desa Gilangharjo Kecamatan Pandak Kabupaten Bantul DIY. Penelitian ini merupakan penelitian eksperimental yaitu menilai pemberian air rebusan daun salam terhadap penurunan kadar asam urat dengan pendekatan Quasi Eksperiment Design dengan menggunakan Non Equivalent Control Group. Cara pengambilan sampel dalam penelitian ini adalah dengan teknik non probability sampling yaitu Purposive Sampling. Jumlah yang diperoleh 36 responden. Pemberian air rebusan daun salam selama 3 hari. Berdasarkan uji Wilcoxon test diperoleh nilai Asymp. Sig. sebesar 0,001 < 0,05, artinya ada pengaruh pemberian air rebusan daun salam terhadap penurunan kadar asam urat pada penderita asam urat di Dusun Kadisoro Gilangharjo Pandak Bantul DIY. Berdasarkan hasil analisis mengenai pemberian air rebusan daun salam terhadap penurunan kadar asam urat pada penderita asam urat di Dusun Kadisoro Desa Gilangharjo Pandak Bantul DIY setelah meminum air rebusan daun salam mengalami penurunan kadar asam urat.
\end{abstract}

Kata kunci: Asam urat, daun salam, lansia, obat herbal, penurunan kadar asam urat.

\footnotetext{
ABSTRACT

Uric acid is a compound in water that is the end product of purine metabolism. Signs and symptoms are inflammation in the joints are depressed, painful, and redness in areas that have occurred uric acid, stiffness and swelling in the joints are depressed. Data posyandu elderly in hamlet kadisoro there are 64 elderly declare mepunyai
} 
complaints of gout. Leaves greetings in Hamlet Kadisoro not been used as herbal medicine because they do not know the function and benefits of the bay leaf. The purpose of this study was to determine the effect of administration of bay leaves (Syzygium polyanthum) on decreasing uric acid levels in gout sufferers in Kadisoro Hamlet, Gilangharjo Village, Pandak District, Bantul Regency, DIY.This research was an experimental study that was assessing the provision of boiled water leaf to decrease uric acid levels with the Quasi Experiment Design using Non-Equivalent Control Group. Sampling method in this research was wi technique of non-probability sampling that was Purposive Sampling. The number of respondents were 36. Provision of boiling water leaves of bay for 3 days.Based on the Wilcoxon test the value of Asymp. Sig. was $0.001<0.05$, meaning that there was an effect of giving bay boiled water to decrease uric acid levels in gout sufferers in Kadisoro Gilangharjo Hamlet Pandak Bantul DIY. Based on the analysis of the administration of bay leaf boiled water to decrease uric acid levels in gout sufferers in Kadisoro Hamlet, Gilangharjo Village, Pandak Bantul DIY after drinking boiled leaves of bay leaves, the uric acid levels decreased.

Keywords: Uric acid, bay leaf, elderly, medicinal herbs, decreased uric acid levels.

\section{PENDAHULUAN}

Kadar asam urat yang tinggi akan menyebabkan peningkatan kristal asam urat yang berbentuk seperti jarum terutama di persendian yang akan menimbulkan rasa sakit. Utomo (2014), menyebutkan bahwa asam urat umumnya banyak diderita oleh laki-laki dibanding perempuan. Pada perempuan akan meningkat setelah menopause karena penurunan fungsi hormone estrogen yang ikut membantu pembuangan asam urat lewat urine.

Rasa sakit akibat asam urat terjadi malam dan pagi hari bangun tidur dan bisa berlangsung selama 4-11 hari. Pengobatan herbal sekarang ini sudah menjadi alternatif lain dari pengobatan modern. Meskipun penggunaan obat-obat tradisional ini belum begitu diminati dikalangan umum, akan tetapi kebiasaan minum jamu masih terlihat dikalangan masyarakat Indonesia, khususnya Jawa dan Madura (Utomo, 2014). Penggunaan obat tradisional merupakan bagian dari kebudayaan Indonesia. Keuntungan dari penggunaan obat tradisional adalah efek samping yang relatif kecil dibandingkan dengan obat yang modern dan pengolahan pada obat tradisional juga sangat sederhana, selain itu harganya murah dan dapat digunakan secara turun-temurun.

Tumbuhan obat yang digunakan sebagai anti hiperurisemia untuk menurunkan kadar asam urat adalah tanaman salam (Syzygium polyanthum Wight). Bagian tanaman yang digunakan adalah daun yang masih segar atau yang sudah dikeringkan. Tanaman salam mengandung tanin, flavonoid, alkaloid, dan minyak atsiri yang terdiri dari sitrat dan eugenol. Daun salam mampu memperbanyak produksi urin (diuretik) sehingga dapat menurunkan kadar asam urat darah (Ningtiyas dan Ramadhian, 2016).

Data penderita asam urat dari Dinas Kesehatan Bantul Lansia Tahun 2015 pada Puskesmas Pandak I dengan jumlah 
41\%. Berdasarkan wawancara dengan kader lansia dari 510 lansia ini tidak semuanya aktif mengikuti posyandu lansia dan 64 orang menyatakan mempunyai keluhan asam urat. Berdasarkan hasil wawancara dengan responden penderita asam urat mereka mengatakan sering kesemutan, nyeri pada daerah sendi dan susah untuk berdiri serta hasil cek asam urat ke puskesmas melebihi batas normal. Tanda dan gejalanya yaitu peradangan pada sendi yang tertekan, terasa nyeri, dan kemerahan pada daerah yang telah terjadi asam urat, kekakuan serta pembengkakan pada sendi yang tertekan.

Hasil dari studi pendahuluan di Dusun Kadisoro daun salamdigunakan untuk penyedap rasa namun belum mengetahui daun salam berkhasiat obat sebagai menurunkan kadar asam urat. Di Dusun Kadisoro banyak yang memiliki pohon salam disekitar rumah namun mereka tidak memanfaatkan sebagai obat herbal karena tidak mengetahui fungsi lain dari daun salam dapat dijadikan obat herbal menurunkan kadar asam urat.

\section{METODE PENELITIAN}

Penelitian ini menggunakan metode rancangan Eksperimen semu (Quasi Experimen Design). Desain yang digunakan dalam penelitian ini adalah Non Equivalent Control Group Design. Eksperimen ini menggunakan dua kelompok yaitu kelompok perlakuan dan ikut mendapat pengamatan yang disebut kelompok control dengan jumlah populasi 64 orang. Dengan metode pada kelompok eksperimen meminum air rebusan daun salam 2 kali sehari selama 3 hari.

\section{HASIL DAN PEMBAHASAN}

\section{Karakteristik Responden}

Distribusi frekuensi karakteristik responden pada lansia penderita asam urat dapat dilihat pada Tabel 1.

Tabel 1. Distribusi Frekuensi

Karakteristik Responden Pada Lansia

Penderita Asam Urat di Dusun Kadisoro

Desa Gilangharjo Kecamatan Pandak Bantul DIY 2018

\begin{tabular}{|c|c|c|c|}
\hline No & $\begin{array}{c}\text { Karakteristik } \\
\text { Responden }\end{array}$ & Frekuensi & $\begin{array}{c}\text { Presentase } \\
(\%)\end{array}$ \\
\hline \multirow{5}{*}{1.} & Umur & & \\
\hline & $45-59$ & 22 & 61,1 \\
\hline & $60-69$ & 13 & 36,1 \\
\hline & $>70$ & 1 & 2,8 \\
\hline & Jumlah & 36 & 100 \\
\hline \multirow{4}{*}{2} & Jenis Kelamin & & \\
\hline & Laki-Laki & 18 & 50,0 \\
\hline & Perempuan & 18 & 50,0 \\
\hline & Jumlah & 36 & 100 \\
\hline \multirow{7}{*}{3} & Pekerjaan & & \\
\hline & Wiraswasta & 11 & 30,6 \\
\hline & Petani & 10 & 27,8 \\
\hline & PNS & 5 & 13,9 \\
\hline & Ibu Rumah & 10 & 27,8 \\
\hline & Tangga & & \\
\hline & Jumlah & 36 & 100 \\
\hline
\end{tabular}
umur responden yang mengalami penyakit asam urat di Dusun Kadisoro Desa Gilangharjo Kecamatan Pandak Bantul DIY 2018 sebanyak 22 responden berusia 45-59 Tahun dengan prosentase $(61,1 \%)$, Jenis kelamin lansia yang mengalami asam urat sama prosentasenya, yaitu $50 \%$ dan 11 lansia 30,6\% memiliki pekerjaan sebagai Wiraswasta.

\section{Hasil Pengukuran Kadar Asam Urat Pre test dan Pos Test}

Hasil pengukuran kadar asam urat responden kelompok eksperimen pada penderita asam urat dapat dilihat pada Tabel 2. 
Tabel 2. Hasil Pengukuran Kadar Asam Urat Responden Kelompok Eksperimen Pada Penderita Asam Urat Dusun Kadisoro Desa Gilangharjo Pandak Bantul DIY Tahun 2018

\begin{tabular}{rrrccc}
\hline No & Umur & Jeni Kelamin & \multicolumn{3}{c}{ Kadar Asam Urat } \\
\cline { 4 - 6 } & & & Pre Test & Post Tes & Ket \\
\hline 1 & 60 & Laki-Laki & 7,5 & 6,2 & Turun \\
2 & 60 & Laki-Laki & 7,9 & 8,2 & Naik \\
3 & 63 & Perempuan & 6,7 & 5,2 & Turun \\
4 & 51 & Perempuan & 7,2 & 6,5 & Turun \\
5 & 46 & Perempuan & 7,5 & 6,0 & Turun \\
6 & 50 & Laki-Laki & 7,4 & 5,5 & Turun \\
7 & 53 & Perempuan & 7,8 & 6,0 & Turun \\
8 & 57 & Perempuan & 8,2 & 6,9 & Turun \\
9 & 59 & Perempuan & 8,3 & 6,4 & Turun \\
10 & 54 & Perempuan & 6,9 & 7,3 & Naik \\
11 & 71 & Laki-Laki & 8,6 & 6,7 & Turun \\
12 & 48 & Laki-Laki & 7,7 & 8,1 & Naik \\
13 & 48 & Perempuan & 6,5 & 4,7 & Turun \\
14 & 48 & Laki-Laki & 8,7 & 6,8 & Turun \\
15 & 59 & Laki-Laki & 7,3 & 7,9 & Naik \\
16 & 52 & Perempuan & 7,6 & 5,6 & Turun \\
17 & 65 & Laki-Laki & 6,9 & 4,3 & Turun \\
18 & 46 & Laki-Laki & 7,8 & 6,1 & Turun \\
\hline
\end{tabular}

Sumber : Data primer diolah 2018

Berdasarkan Tabel 2 responden penderita asam urat di dusun Kadisoro Desa Gilangharjo Pandak Bantul DIY, lansia yang meminum rebusan daun salam sebanyak 18 lansia. Kadar asam urat yang meminum rebusan daun salam sebanyak 18 lansia, terdapat 14 lansia kadar asam uratnya turun dan 4 lansia kadar asam uratnya naik.

Hasil pengukuran kadar asam urat responden kelompok kontrol pada penderita asam urat dapat dilihat pada Tabel 3. Berdasarkan Tabel 3 responden penderita asam urat di dusun Kadisoro Desa Gilangharjo Pandak Bantul DIY, lansia yang tidak meminum rebusan daun salam sebanyak 18 lansia. Kadar asam urat lansia yang tidak minum rebusan daun salam terdapat 15 , lansia kadar asam uratnya naik dan 3 lansia yang tidak meminum air rebusan daun salam kadar asam uratnya turun.

Distribusi frekuensi kadar asam urat responden kelompok eksperimen pada penderita asam urat dapat dilihat pada Tabel 4. Berdasarkan Tabel 4 bahwa distribusi frekuensi kadar asam urat pada kelompok eksperimen pada penderita asam urat di Dusun Kadisoro Desa Gilangharjo Pandak Bantul DIY tahun 2018 kategori pengukuran naik jumlah 4 orang dengan presentase 22,2\%, sedangkan kategori pengukuran turun jumlah 14 orang dengan prosentase $77,8 \%$. Hal ini menunjukan adanya pengaruh pemberian air rebusan daun salam terhadap penurunan kadar asam urat dengan presentase keberhasilan 77,8\%. 
Tabel 3. Hasil Pengukuran Kadar Asam Urat Responden Kelompok Kontrol Pada Penderita Asam Urat Dusun Kadisoro Desa Gilangharjo Pandak Bantul DIY Tahun 2018

\begin{tabular}{rrcccc}
\hline No & \multirow{2}{*}{ Umur } & Jeni Kelamin & \multicolumn{3}{c}{ Kadar Asam Urat } \\
\cline { 4 - 6 } & & & Pre Test & Post Tes & Ket \\
\hline $\mathbf{1}$ & 53 & Laki-Laki & 7,9 & 8,1 & Naik \\
$\mathbf{2}$ & 53 & Perempuan & 7,5 & 7,9 & Naik \\
$\mathbf{3}$ & 64 & Perempuan & 8,1 & 8,6 & Naik \\
$\mathbf{4}$ & 59 & Laki-Laki & 7,5 & 8,0 & Naik \\
$\mathbf{5}$ & 64 & Perempuan & 7,5 & 8,2 & Naik \\
$\mathbf{6}$ & 69 & Laki-Laki & 6,9 & 7,2 & Naik \\
$\mathbf{7}$ & 60 & Laki-Laki & 7,8 & 8,0 & Naik \\
$\mathbf{8}$ & 59 & Perempuan & 7,3 & 7,8 & Naik \\
$\mathbf{9}$ & 48 & Laki-Laki & 8,1 & 7,2 & Turun \\
$\mathbf{1 0}$ & 66 & Laki-Laki & 7,4 & 7,9 & Naik \\
$\mathbf{1 1}$ & 68 & Perempuan & 6,5 & 7,2 & Naik \\
$\mathbf{1 2}$ & 48 & Perempuan & 6,3 & 6,7 & Naik \\
$\mathbf{1 3}$ & 60 & Perempuan & 6,6 & 7,1 & Naik \\
$\mathbf{1 4}$ & 62 & Laki-Laki & 7,5 & 8,1 & Naik \\
$\mathbf{1 5}$ & 58 & Laki-Laki & 7,2 & 7,8 & Naik \\
$\mathbf{1 6}$ & 67 & Perempuan & 6,4 & 6,9 & Naik \\
$\mathbf{1 7}$ & 49 & Perempuan & 7,5 & 6,8 & Turun \\
$\mathbf{1 8}$ & 49 & Laki-Laki & 7,3 & 6,5 & Turun \\
\hline Sunnyyyy
\end{tabular}

Sumber : Data primer diolah 2018

Tabel 4. Distribusi Frekuensi Kadar Asam Urat Responden Kelompok Eksperimen Pada Penderita Asam Urat Dusun Kadisoro Desa Gilangharjo Pandak Bantul DIY Tahun 2018

\begin{tabular}{ccc}
\hline \multirow{2}{*}{$\begin{array}{c}\text { Kategori } \\
\text { Pengukuran }\end{array}$} & \multicolumn{2}{c}{ Hasil Ukur } \\
\cline { 2 - 3 } & Frekuensi & $\begin{array}{c}\text { Presentase } \\
(\boldsymbol{\%})\end{array}$ \\
\hline Naik & 4 & $22,2 \%$ \\
Turun & 14 & $77,8 \%$ \\
\hline Total & 18 & 100 \\
\hline
\end{tabular}

Sumber : Data primer diolah 2018

Berdasarkan Tabel 5 distribusin frekuensi kadar asam urat pada kelompok kontrol pada penderita asam urat di Dusun Kadisoro Desa Gilangharjo Pandak Bantul DIY tahun 2018 kategori pengukuran naik berjumlah 15 orang dengan presentase
$83,3 \%$, sedangkan kategori pengukuran turun jumlah 3 orang dengan prosentase $16,7 \%$. Hal ini menunjukan tidak adanya perubahan yang signifikan sebelum dan sesudah tanpa diberikan perlakuan.

Tabel 5. Distribusi Frekuensi Kadar Asam Urat Responden Kelompok Kontrol Pada Penderita Asam Urat Dusun Kadisoro Desa Gilangharjo Pandak Bantul DIY Tahun 2018

\begin{tabular}{ccc}
\hline \multirow{2}{*}{$\begin{array}{c}\text { Kategori } \\
\text { Pengukuran }\end{array}$} & \multicolumn{2}{c}{ Hasil Ukur } \\
\cline { 2 - 3 } & Frekuensi & $\begin{array}{c}\text { Presentase } \\
(\boldsymbol{\%})\end{array}$ \\
\hline Naik & 15 & $83.3 \%$ \\
Turun & 3 & $16,7 \%$ \\
\hline Total & 18 & 100 \\
\hline
\end{tabular}

Sumber : Data primer diolah 2018 
3. Pengaruh Pemberian Air Rebusan Daun Salam Terhadap Penurunan Kadar Asam Urat Pada Penderita Asam Urat di Dusun Kadisoro Desa Gilangharjo Pandak Bantul

\section{a. Pengujian Kadar Asam Urat Pada Kelompok Eksperimen}

Bahwa dari 18 responden penderita asam urat di dusun Kadisoro Desa Gilangharjo Pandak Bantul DIY, lansia kelompok eksperimen yang meminum rebusan daun salam. Diketahui Negativ Ranks atau selisih (negatif) antara hasil kadar asam urat untuk Pre test dan Post test adalah 14, nilai 14 ini menunjukkan ada penurunan dari nilai Pre test ke nilai Post test. Jadi dari 18 lansia yang kadar asam uratnya turun ada 14 lansia. Sedangkan nilai Positive Ranks ada 4 maka lansia yang meminum air rebusan daun salam namun mengalami kenaikan kadar asam urat terdapat 4 lansia. Diketahui nilai Ties adalah kesamaan nilai pre test dan postest adalah 0 maka tidak ada nilai yang sama antara nilai pretest dan posttest.

Hasil uji Wilcoxon test statistics diperoleh nilai Asymp. Sig. sebesar 0,001 $<0,05$ maka Ha diterima dan Ho ditolak yang artinya ada pengaruh pemberian air rebusan daun salam terhadap penurunan kadar asam urat pada penderita asam urat di Dusun Kadisoro Gilangharjo Pandak Bantul DIY.

\section{b. Pengujian Kadar Asam Urat Pada Kelompok Kontrol}

Bahwa dari 18 responden penderita asam urat di dusun Kadisoro Desa Gilangharjo Pandak Bantul DIY, lansia kelompok kontrol yang tidak meminum rebusan daun salam. Diketahui Negativ Ranks atau selisih (negatif) antara hasil kadar asam urat untuk Pre test dan Post test adalah 3, nilai 3 ini menunjukkan ada penurunan dari nilai Pre test ke nilai Post tes. Jadi dari 18 lansia yang kadar asam uratnya turun ada 3 lansia. Sedangkan nilai Positive Ranks ada 15 maka lansia yang tidak meminum air rebusan daun salam namun mengalami kenaikan kadar asam urat terdapat 15 lansia. Diketahui nilai Ties adalah kesamaan nilai pretest dan postes adalah 0 maka tidak ada nilai yang sama antara nilai pretest dan posttest.

Hasil uji Wilcoxon test statistics diperoleh nilai Asymp. Sig. sebesar 0,120 $>0,05$ hal ini menunjukan bahwa tidak terdapat perbedaan pada sebelum dan sesudah dilakukan penelitian pada kelompok kontrol pada penderita asam urat di Dusun Kadisoro Gilangharjo Pandak Bantul DIY.

\section{Kadar Asam Urat Pada Lansia Berdasarkan Karakteristik}

Penelitian ini dilakukan di Dusun Kadisoro Desa Gilangharjo Pandak Bantul DIY tahun 2018 dengan jumlah responden sebanyak 36 orang berdasarkan kriteria inklusi. Dalam penelitian ini terdapat beberapa karakteristik responden yaitu umur, jenis kelamin, pekerjaan. Berdasarkan Tabel 1 diketahui responden memiliki umur yang bervariasi. Sebanyak 22 responden berusia 45-59 tahun dengan prosentase $(61,1 \%), 13$ responden dengan berusia 60-69 ahun dengan prosentase $(36,1 \%), 1$ responden berusia $>70$ Tahun dengan prosentase $(2,8 \%)$. Peningkatan asam urat yang terjadi pada penelitian ini disebabkan karena pengaruh faktor usia, karena semakin meningkat usia seseorang maka kemungkinan terjadinya peningkatan kadar asam urat dalam tubuh juga semakin besar. Faktor lain yang mempengaruhi terjadinya peningkatan kadar asam urat tersebut diantaranya gaya hidup yang suka mengkonsumsi makanan tinggi purin sehingga terjadi peningkatan kadar asam urat dalam tubuh. Terganggunya pengeluaran asam urat dari tubuh juga menjadi penyebab terjadinya peningkatan asam urat dalam tubuh. 
Jenis kelamin, ditemukan jenis kelamin laki-laki yang mengalami asam urat sebanyak 18 dengan presentase $50 \%$. Sedangkan jenis kelamin perempuan sebanyak 18 dengan presentase $50 \%$. Kadar asam urat asam urat normal lakilaki 3,5-7 $\mathrm{mg} / \mathrm{dl}$ dan perempuan 2,6-6 $\mathrm{mg} / \mathrm{dl}$ (Wibowo, 2015). Kadar rata-rata asam urat di dalam darah tergantung pada usia dan jenis kelamin. Penyakit ini cenderung dialami pria. Menurut teori Wibowo (2015) pria lebih rentan terkena penyakit asam urat dibandingkan wanita. Hormone estrogen pada wanita berpengaruh pada proses pembuangan asam urat melalui urine. Hormone estrogen diproduksi secara alami selama masa produktif. Karena itu, pada wanita biasanya gejala asam urat baru muncul saat memasuki masa menopause.

Jenis pekerjaan responden baik kelompok eksperimen maupun kelompok control dimana sebanyak 11 lansia dengan prosentase 30,6 \% memiliki pekerjaan sebagai Wiraswasta. lansia yang memiliki profesi sebagai petani sebanyak 10 dengan prosentase $27,8 \%$. Lansia yang memiliki profesi sebagai PNS sebanyak 5 orang dengan prosentase $13,9 \%$, dan lansia yang berprofesi sebagai ibu rumah tangga sebanyak 10 dengan prosentase sebanyak $27,8 \%$. Pekerjaan juga dapat mempengaruhi terjadinya asam urat. Seperti pekerjaan yang ringan dengan pengaturan pola makan yang tidak terkontrol serta minimnya waktu olah raga dapat memicu kegemukan yang dapat menyebabkan asam urat. Hal tersebut dapat dijadikan gambaran tentang bahaya asam urat dengan faktor-faktor yang mempengaruhi sesorang bisa terkena asam urat khusunya pada laki-laki yang sudah lansia dan wanita yang sudah mengalami menopause yang disebabkan oleh menurunnya kadar hormon estrogen karena lanjut usia dan pola hidup yang kurang baik serta kurangnya kesadaran tentang bahaya asam urat.

\section{Kadar Asam Urat Pada Lansia Kelompok Kontrol Yang Tidak Diberikan Air Rebusan Daun Salam}

Dari 18 responden kadar asam urat pada kelompok kontrol pada penderita asam urat di Dusun Kadisoro Desa Gilangharjo Pandak Bantul DIY tahun 2018 kategori pengukuran naik jumlah 15 orang dengan presentase 83,3\%, sedangkan kategori pengukuran turun jumlah 3 orang dengan prosentase 16,7\%. Artinya bahwa sebagian besar $83,3 \%$ lansia kadar asam uratnya naik karena tidak meminum air rebusan daun salam yang mengandung tanin, flavonoid, alkaloid, dan minyak atsiri yang terdiri dari sitrat dan eugenol. Daun salam mampu memperbanyak produksi urin (diuretik) sehingga dapat menurunkan kadar asam urat darah (Ningtiyas dan Ramadhian, 2016).

Kadar asam urat tinggi dapat dilihat dari berbagai faktor antara lain nutrisi (konsumsi makanan yang tinggi purin), obesitas, umur, jenis kelamin, konsumsi alkohol, obat obatan (Purwaningsih Tinah, 2010). Produksi asam urat di dalam tubuh meningkat ini merupakan penyebab karena mengkonsumsi makanan yang berkadar tinggi purin seperti daging, jeroan, kacang, kangkung, kembang kol, buncis, dan kepiting. Keadaan ini akan membuat metabolisme makanan tersebut membentuk asam urat yang akhirnya membuat tingginya kadar asam urat dalam darah (Hazeliawati, 2014). Pada lansia kelompok kontrol yang tidak diberikan air rebusan daun salam cenderung tidak berhati-hati saat mengkonsumsi makanan yang tinggi purin ini dikarenakan kurangnya pengetahuan tentang asam urat dan hal-hal yang dapat memicu peningkatan kadar asam urat dalam darah. Terdapat $3(15 \%)$ lansia kadar asam uratnya turun pada kelompok kontrol yang tidak diberikan air rebusan daun salam namun kadar asam uratnya turun ini berdasarkan observasi dikarenakan 
responden menghindari makanan mengandung purin tinggi dan mengkonsumsi makanan yang rendah purin , minum air putih yang banyak dan sering melakukan olahraga.

\section{Kadar Asam Urat Pada Lansia Kelompok eksperimen Yang Diberikan Air Rebusan Daun Salam}

Pada 18 kelompok eksperimen penderita asam urat yang meminum air rebusan daun salam di Dusun Kadisoro Desa Gilangharjo Pandak Bantul DIY tahun 2018 kategori pengukuran naik jumlah 4 orang dengan presentase $22,2 \%$, sedangkan kategori pengukuran turun jumlah 14 orang dengan prosentase $77,8 \%$. Artinya bahwa sebagian besar $77,8 \%$ lansia kadar asam uratnya turun karena meminum air rebusan daun salam yang mengandung tanin, flavonoid, alkaloid, dan minyak atsiri yang terdiri dari sitrat dan eugenol. Daun salam mampu memperbanyak produksi urin (diuretik) sehingga dapat menurunkan kadar asam urat darah (Ningtiyas dan Ramadhian, 2016). Penggunaan obat herbal ini sangat menguntungkan karena harganya terjangkau dan mudah didapat. Keuntungan dari penggunaan obat tradisional adalah efek samping yang relatif kecil dibandingkan dengan obat yang modern dan pengolahan pada obat tradisional juga sangat sederhana, selain itu harganya murah dan dapat digunakan secara turun-temurun.

Terdapat kategori pengukuran naik jumlah 4 orang dengan presentase 22,2\% pada kelompok eksperimen yang meminum air rebusan daun salam. Kadar asam urat tinggi dapat dilihat dari berbagai faktor antara lain nutrisi (konsumsi makanan yang tinggi purin), obesitas, umur, jenis kelamin, konsumsi alkohol, obat obatan (Purwaningsih, 2010). Produksi asam urat di dalam tubuh meningkat ini merupakan penyebab karena mengkonsumsi makanan yang berkadar tinggi purin seperti daging, jeroan, kacang, kangkung, kembang kol, buncis, dan kepiting. Keadaan ini akan membuat metabolisme makanan tersebut membentuk asam urat yang akhirnya membuat tingginya kadar asam urat dalam darah (Hazeliawati, 2014).

Pada 4 responden kelompok eksperimen yang meminum air rebusan daun salam namun mengalami peningkatan kadar asam urat ini diakibatkan mengkonsumsi makanan yang tinggi purin setiap hari, selain itu responden jarang meminum air putih. Meminum air putih yang cukup dapat juga membantu mengurangi kadar purin dalam tubuh, apabila kadar purin tidak dikeluarkan makan dari hari ke hari kadar purin dalam tubuh akan bertambah dan kadar asam urat di dalam darah juga akan naik.

\section{Kadar Asam Urat Lansia Penderita Asam Urat Sebelum dan Sesudah Diberikan Perlakuan Baik Kelompok Kontrol Maupun Kelompok Eksperimen}

Dari hasil analisis menunjukkan bahwa penelitian yang dilakukan dengan memberikan air rebusan daun salam kepada 18 responden kelompok eksperimen dengan meminum air rebusan daun salam 2 kali sehari selama 3 hari pemberian terhadap penurunan kadar asam urat pada kelompok eksperimen. Hasil uji Wilcoxon test statistics diperoleh nilai Asymp. Sig. sebesar 0,001 < 0,05. Angka ini jika dibandingkan dengan signifikasi atau pemaknaan yang ditentukan nilainya jauh lebih kecil. Dengan demikian dapat dikatakan bahwa Ha diterima terdapat perbedaan yang signifikan atau ada pengaruh sebelum dan sesudah diberikan air rebusan daun salam pada lansia terhadap penurunan kadar asam urat pada penderita asam urat di Dusun Kadisoro Desa Gilangharjo Pandak Bantul DIY tahun 2017. Hal ini dapat 
dibuktikan dengan hasil penelitian yang menunjukan terdapat perbedaan antara responden yang diberikan air rebusan daun salam dengan responden yang tidak diberikan air rebusan daun salam.

Penelitian ini sejalur dengan penelitian Darrusalam (2016) dengan hasil analisis menunjukkan perbandingan kadar asam urat sebelum dan sesudah pemberian air rebusan daun salam, terdapat 19 responden dengan hasil setelah pemberian rebusan daun salam lebih rendah daripada sebelum intervensi, terdapat 5 responden mengalami kenaikan kadar asam urat setelah pemberian air rebusan daun salam dan tidak ada responden yang mempunyai kadar asam urat yang sama pada sebelum maupun sesudah intervensi.

Berdasarkan hasil penelitian dari Hazeliawati (2014), hasil pengukuran nilai rata-rata kadar asam urat setelah diberikan perlakuan pemberian air rebusan daun salam menunjukkan penurunan kadar asam urat dari nilai $10,01 \mathrm{mg} / \mathrm{dl}$ menjadi $4,78 \mathrm{mg} / \mathrm{dl}$. Selain itu hasil uji beda post test pada kelompok intervensi dan kelompok control menunjukkan nilai sig 0,002 yang artinya bahwa ada perbedaan pada kadar asam urat pada kelompok intervensi dan kelompok kontrol. Kelompok intervensi yang telah diberikan air rebusan daun salam menunjukkan penurunan kadar asam urat pada hari ke 3 .

Menurut penelitian dari Madyastuti dan Septiadi (2014) flavonoid yang terkandung pada daun salam dapat mengikat senyawa enzim Xathine Oxidase sehingga dapat menurunkan pembentukan Xathine yang dapat membentuk asam urat. Struktur Flavonoid yang mempunyai ikatan rangkap dapat dengan mudah mengikat senyawa enzim Xathine Oxidase sehingga dalam metabolisme pembentukan asam urat produksi Xathine dapat di kontrol. Hal ini berpengaruh dalam kadar asam urat dalam darah yang dapat berangsur-angsur menurun.
Mekanisme yang mengontrol metabolisme pembentukan asam urat berlangsung di hati yang dipengaruhi oleh enzim xathine oxidase.

Asam urat sendiri tidak berbahaya, karena asam urat dapat disekresikan dari tubuh. Proses sekresi melibatkan ginjal dan usus. Pada ginjal asam urat disaring tidak semuanya dikeluarkan. Proses penyaringan ini bertujuan untuk menyeimbangkan kadar asam urat dalam tubuh. Asam urat disimpan dalam jaringan kulit, persendian dan ginjal. Perubahan dimana senyawa asam urat menjadi monosodium urat terjadi bila tubuh tidak mampu menetralisir penumpukan asam urat. Senyawa flavonoid yang terkandung pada daun salam berperan menghambat kinerja enzim xathine oxidase, kemampuan flavonoid dalam menghambat aktivitas xanthine oxidase sangat terkait dengan strukturnya. Struktur flavonoid secara umum terdiri dari tiga cincin benzena. Di mana atom $\mathrm{C}$ pada struktur tersebut mempunyai ikatan rangkap. Di mana struktur dengan mudah mengikat enzim Xathine Oxidase sehingga pembentukn xathine berkurang dan produksi asam urat pun berkurang. Hal tersebut menggambarkan hasil pengamatan terhadap penderita asam urat setelah diberikan rebusan daun salam yang dapat membantu menurunkan produksi xathine yang merupakan zat awal dalam pembentukan asam urat sehingga dapat menurunkan kadar asam urat dalam darah (Madyastuti dan Septiadi, 2014).

Hal tersebut dapat dijadikan gambaran bahwa penderita asam urat akan mengalami penurunan kadar asam urat. Ini berarti penggunaan terapi rebusan daun salam pada penderita asam urat di Dusun Kadisoro Desa Gilangharjo Pandak Bantul berpengaruh dalam penurunan kadar asam urat karena rebusan daun salam dapat menyeimbangkan enzim Xathine Oxidase sehingga metabolism purin terkontrol dan 
produksi asam urat menurun. Namun terapi rebusan daun salam ini tidak dapat menurunkan secara drastik penurunan asam urat. Hal ini dibuktikan dengan sebanyak 18 lansia yang meminum rebusan daun salam, terdapat 14 lansia kadar asam uratnya turun namun terdapat 4 lansia kadar asam uratnya naik walaupun sudah meminum air rebusan daun salam. hal ini desebabkan oleh kondisi tingginya kadar asam urat yang terkadung dalam darah dan pola hidup tidak sehat yang dijalani, serta usia yang menjadi kendala karena penurun hormone estrogen yang tidak dapat dicegah.

Bahwa hasil uji Wilcoxon test statistics diperoleh nilai Asymp. Sig. sebesar $0,120>0,05$ hal ini menunjukan bahwa tidak terdapat perbedaan pada sebelum dan sesudah dilakukan penelitian pada kelompok kontrol pada penderita asam urat di Dusun Kadisoro Gilangharjo Pandak Bantul DIY. Hal ini dapat dilihat pada tabel 4.10 dari 18 lansia yang kadar asam uratnya turun ada 3 lansia tidak meminum air rebusan daun salam. Sedangkan nilai Positive Ranks ada 15 maka lansia yang tidak meminum air rebusan daun salam namun mengalami kenaikan kadar asam urat terdapat 15 lansia.

Menurut Ulya (2017), Asam urat adalah senyawa dalam air yang merupakan hasil akhir metabolism purin.
Secara alamiah purin terdapat dalam tubuh kita dan dijumpai pada semua makanan dari sel hidup, yakni makanan dari tanaman berupa sayuran, buah, dan kacang-kacangan atau hewan berupa daging, jerohan, ikan dan makanan kaleng. Apabila kadar asam urat diatas normal kondisi ini disebut hiperurisemia. Berdasarkan Tabel 5 terdapat 15 lansia yang pada kelompok kontrol kadar asam uratnya naik dikarenakan tidak bisa menghindari makanan yang mengandung purin tinggi selain itu responden jarang meminum air putih yang dapat membantu sekresi zat purin dalam ginjal. Namun terdapat 3 lansia kelompok kontrol mengalami penurunan kadar asam urat ini dikarenakan responden dapat mengontrol makanan yang rendah purin, banyak mengkonsumsi buah-buahan dan air putih dan runtin olahraga.

\section{KESIMPULAN}

Terdapat pengaruh sebelum dan sesudah diberikan air rebusan daun salam pada lansia terhadap penurunan kadar asam urat pada penderita asam urat di Dusun Kadisoro Desa Gilangharjo Pandak Bantul DIY tahun 2017.

\section{UCAPAN TERIMA KASIH}

Stikes Surya Global Yogyakarta.

\section{DAFTAR PUSTAKA}

Alifiasari, D. (2010). Komplikasi Asam Urat. http://e-bookspdf.org. Diakses Pada Tanggal 2 November 2017.

Andriani, A. \& Chaidir. (2016). Pengaruh Pemberian Air Rebusan Daun Salam (Syzygium Polyanthum) Terhadap Penurunan Kadar Asam Urat. Program Studi DIII Keperawatan. STIKes Yarsi Sumbar Bukittinggi.

Anonim. (2009). Tinjauan Uridis Terhadap Perlindungan Konsumsi atas Beredarnya Obat Tradisional Yang Tidak Mencantumkan Label Berbahasa Indonesia Pada Kemasanya, 8. http://www.lawskripsi.com. Diakses tanggal 5 November 2017. Anonim. (2017). Antisipasi lonjakan lansia. https://kompas.id/baca/ilmu-pengetahuanteknologi/2017/05/20/antisipasi-lonjakan-lansia/. Atau https:// www. 
pressreader.com/indonesia/kompas/20170520/281831463668837. Diakses pada 18 November 2017.

Apriyanti, M. (2016). Meracik sendiri obt dan menu sehat bagi penderita asam urat. Pustaka Baru Press, Yogyakarta.

Azwar, A. DARFK. (2010). Atlas Obat Indonesia. Buku 2. Jilid 3. Salemba Medika, Jakarta.

Cumayunaro, A. (2017). Rebusan Daun Salam Untuk Penurunan Kadar Asam Urat Dan Intensitas Nyeri Arthritis Gout Di Puskesmas Andalas Padang. Program Studi Keperawatan. Stikes Ranah Minang Padang.

Darrusallam, M. (2016). Peran Air Rebusan Daun Salam (Syzgium polyanthum) Dalam Menurunkan Kadar Asam Urat. Program Studi Ilmu Keperawatan. Stikes Jenderal Achmad Yani Yogyakarta.

Diantari. (2012). Pengaruh Asupan Purin dan Cairan Terhadap Kadar Asam Urat Pada Wanita Usia 50-60 Tahun di Kecamatan Gajah Mungkur, Semarang. Program Studi Ilmu Gizi. Fakultas Kedokteran. Universitas Diponegoro.

Hazielawati, V. (2014). Pengaruh Pemberian Air Rebusan Daun Salam Terhadap Kadar Asam Urat Pada Lansia Penderita Arthritis Gout di Dusun Modinan Gamping Sleman Yogyakarta. Program Studi Ilmu Keperawatan. Sekolah Tinggi Ilmu Kesehatan 'Aisiyah Yogyakarta.

Hello Health Group. (2017). Asam Urat (Encok): Penyebab, Obat, dan Gejala Penyakit. https://hellosehat.com/penyakit/asam-urat-encok/. Diakses Tanggal 23 November 2017.

Khadijah, S. (2017). Asam Urat: Gejala, Penyebab, Pengobatan dan Pencegahan. https://www.cermati.com/artikel/asam-urat-gejala-penyebab-pengobatan-danpencegahannya. Diakses Tanggal 5 November 2017. Jam 14.30 WIB.s

Krisnatuti, D., Yenrina, R. \& Uripi, V. (2008). Perencanaan Menu Untuk Penderita Asam Urat. Penebar Swadaya, Jakarta.

Madyastuti, L. \&Septiadi, D. (2014). Rebusan Daun Salam Menurunkan Kadar Asam Urat Pasien Gout . Program Studi Ilmu Keperawatan. Fakultas Ilmu Kesehatan Universitas Gresik.

Maryanti. (1989). Ekstrak Air Daun Salam Memiliki Efek Hipoglikemia Pada Tikus Penderita Diabetes Mellitus. FF UGM, Yogyakarta.

Notoatmodjo S, (2005). Metode Penelitian Kesehatan. Rineka Cipta, Jakarta. , (2012). Metode Penelitian Kesehatan. Rineka Cipta, Jakarta.

Nursalam. (2016). Konsep dan Penerapan Metodologi Penelitian Keperawatan. Info Medika, Jakarta.

Profil Desa Gilangharjo. (2017). http://gilangharjo.bantulkab.go.id/index.php/first. Diakses pada tanggal 21 februari 2018.

Purwaningsih. (2010). Faktor-Faktor Risiko Hiperurisemia Studi Kasus Di Rsu Kardinah Kota Tegal. Tesis. Program Studi Magister Epidemiologi Universitas Diponegoro Semarang.

Pusat Data dan Informasi Kesehatan RI. (2013). Gambaran Kesehatan Lanjut Usia di Indonesia. Buletin Jendela Data dan Informasi Kesehatan: Semester 1:9-10.

Ramadhian, Ningtiyas. (2016). Efektivitas Ekstrak Daun Salam untuk Menurunkan Kadar Asam Urat pada Penderita Artritis Gout. Fakultas Kedokteran, Universitas Lampung.

Riwidikdo. (2012). Statistik Kesehatan. Nuha Medika, Yogyakarta. 
Riyanto, A. (2011). Aplikasi Metodologi Penelitian Kesehatan. Nuha Medika. Yogyakarta.

Robinson, T. (1995). Kandungan Organik Tumbuhan Tinggi. 6th ed. Institut Teknologi Bandung, Bandung.

Saryono. (2011). Metodologi Penelitian Kesehatan. Mitra Cendikia Press, Yogyakarta.

Sinaga, A. F., Bodhi, W. \& Lolo, W. A. (2014). Uji Efek Ekstrak Etanol Daun Salam (Syzygium polyanthum (Wight.) Walp) terhadap Penurunan Kadar Asam Urat Tikus Putih Jantan Galur Wistar (Rattus novergicus L.) diinduksi Potaium Oksonat. PHARMACON-Jurnal Ilmiah Farmasi, 3(2), pp. 141-145.

Sudewi, R. (1992). Isolasi dan Uji Daya Antibiotik Daun Salam (Eugenropolynthes wight). FF UGM, Yogyakarta.

Ulya. (2017). Asam urat, Hiperurisemia dan Artritis Gout. http://ulyadays.com/asamurat-hiperurisemia/. Diakses pada Tanggal 5 Maret 2018.

Utomo, F. (2014). Pengaruh pemberian air rebusan daun salam terhadap penurunan kadar asam urat pada lansia di Tegalsari Salatiga. Program Studi Ilmu Keperawatan . Universitas Satyawicana Salatiga.

Wibowo, S. (2015). Tanaman Sakti Tumpas Macam-Macam Penyakit. Pustaka Makmur, Jakarta Timur. 